\title{
Erratum to: Teaching and Learning Medical Biochemistry: Perspectives from a Student and an Educator
}

\author{
Mehdi Afshar $^{1}$ - Zhiyong Han ${ }^{1}$
}

Published online: 20 March 2015

(C) International Association of Medical Science Educators 2015

Erratum to: Med Sci Educ (2014) 24:339-341

DOI 10.1007/s40670-014-0004-7

Reference 7 was published with an error. It appears correctly below:

Fulton TB, Ronner P, Lindsley JE (2012) Medical biochemistry in the era of competencies: is it time for the Krebs cycle to go? Med Sci Educ 22(1):29-32

The online version of the original article can be found at http://dx.doi.org/ 10.1007/s40670-014-0004-7.

Zhiyong Han

zyhan@gwu.edu

Department of Biochemistry and Molecular Medicine, the George

Washington University School of Medicine and Health Sciences,

Room 547, Ross Hall, 2300 Eye Street NW, Washington,

DC 20037, USA 